\title{
RISKS FOR ADVERSE PREGNANCY OUTCOMES AND INFECTIONS IN DAYCARE WORKERS: AN OVERVIEW OF CURRENT EPIDEMIOLOGICAL EVIDENCE AND IMPLICATIONS FOR PRIMARY PREVENTION
}

\author{
ANCA RADAUCEANU ${ }^{1}$ and MYRIAM BOUSLAMA ${ }^{2}$ \\ ${ }^{1}$ French Research and Safety Institute for the Prevention of Occupational Accidents and Diseases (INRS), \\ Vandœuvre-lès-Nancy Cedex, France \\ Department of Epidemiology \\ ${ }^{2}$ French Research and Safety Institute for the Prevention of Occupational Accidents and Diseases (INRS), Paris, France \\ Department of Expertise and Technical Advice
}

\begin{abstract}
Childcare providers are overwhelmingly women of childbearing age. Occupational risks in this sector include exposure to biological (infectious) or physical (standing, carrying loads) hazards, many of which are associated with adverse pregnancy outcomes such as children with congenital infections, low birth weight or prematurity. Here, the authors examined literature on pregnancy outcomes and infectious hazards related to employment in daycare settings. Overall, 33 original studies (10 reporting pregnancy issues, 23 focusing on infectious risks) published in 1980-2018 were retained following a Medline search. Pregnancy issues in daycare workers have rarely been studied, and inconsistent risks of spontaneous abortion, congenital malformations and fetal growth retardation have been reported. Literature pertaining to infectious risks in daycare settings is extensive. The risk of a primary cytomegalovirus infection during pregnancy was increased for daycare workers caring for $>6$ children and younger children, changing diapers $\geq 3$ days/week, not wearing gloves when changing diapers, and having employment in daycare for $\leq 2$ years. Personal factors (nulliparity, ethnicity) were also independent risk factors. Parvovirus B19 (B19V) infections appear to be related to employment in daycare, but also to having one's own children and an increased number of siblings. Consequently, the risk of a primary B19V infection during an outbreak is of most concern among younger nulliparous workers caring for large numbers of young infected children. Since the main occupational hazard is viral infection, feasible prevention strategies include improving workers' awareness, serological monitoring during pregnancy, educating on appropriate preventive measures, and ensuring age-appropriate immunization of children and staff in childcare facilities. Int J Occup Med Environ Health. 2020;33(6):733-56
\end{abstract}

Key words:

pregnancy, occupational exposure, schools, nurseries, child daycare centers, viral disease

Received: September 20, 2019. Accepted: June 25, 2020.

Corresponding author: Anca Radauceanu, French Research and Safety Institute for the Prevention of Occupational Accidents and Diseases (INRS), Department of Epidemiology, 1 rue du Morvan, 54519 Vandœuvre-lès-Nancy Cedex, France (e-mail: anca.radauceanu@inrs.fr). 


\section{INTRODUCTION}

In the last century, women's participation in the workforce of industrialized countries has risen substantially and, as a consequence, working during pregnancy has become more common [1]. Maternal employment in specific occupational groups may potentially affect all stages of pregnancy, with increased risks of fetal death, birth defects, preterm delivery, intrauterine growth restriction, as well as long-term effects in the offspring.

The numbers of female workers in the healthcare and daycare sectors are rapidly increasing worldwide, and childcare is a profession where women of reproductive age are more likely to be employed [1,2]. Although the risk of adverse reproductive outcomes has been extensively assessed among healthcare workers [3,4], few studies have reported on adverse pregnancy outcomes in daycare and nursery staff. Childcare workers are mainly exposed to biological, physical and chemical hazards in their workplaces as part of care, recreational and janitorial tasks. Since childcare workers are frequently exposed to numerous excreta-borne viruses, such as cytomegalovirus (CMV), parvovirus B19 (B19V), varicella-zoster virus (VZV), and rubella virus, most research conducted to date has examined the risks for pregnancy related to viral infections. Congenital infections may cause serious fetal diseases, such as cognitive and motor deficits, visual or hearing impairments, central nervous system diseases (CMV), fetal hydrops or fetal death (B19V), miscarriage or congenital abnormalities (VZV), deafness, cataracts, microcephaly and other congenital birth defects (rubella virus) $[5,6]$.

Just as a point of interest, the risk of maternal infections with CMV during pregnancy has been reported to be increased among women employed in childcare centers, whereas CMV seronegative hospital workers caring for young children and infants are not at an increased risk [7].

Physical effort exerted by daycare staff may be designated as a "moderate" to "high" physical load [8] but, to the best of the authors' knowledge, no published studies present the effects of physical demands on pregnancy issues specifically for daycare workers. Workers in the childcare sector are exposed to psychosocial factors, such as job stress [9], but no data about the effects of work-related stress on pregnancy outcomes in childcare staff have been reported.

The objective of this review was to give an overview of previously published literature on the risk of adverse pregnancy outcomes and infectious hazards related to maternal employment in daycare settings. Accordingly, some issues of interest, such as preventing infections and protecting pregnant caregivers, were discussed.

\section{METHODS}

\section{Literature search strategy}

Published literature was identified through a Medline database electronic search. Articles relating to adverse pregnancy outcomes and risks for infections in daycare settings were identified. The search was carried out according to PRISMA guidelines [10], and was restricted to the period of 1980-2018 and to articles published in English.

The search strategy was mainly constructed using MeSH terms and additional queries with freely-selected texts (without MeSH terms). The exposed population was identified through the following MeSH terms: "child day care centers" or "nurseries" associated with "occupational exposure" or "risk factors" or "maternal exposure" or "virus disease." The outcomes of interest were selected using the following MeSH terms: "pregnancy," "pregnancy outcome," "congenital abnormalities," "abortion, spontaneous," "fetal death," "stillbirth," "premature birth," and "infant, premature." Adverse effects on fertility and menstrual function were not addressed in this article.

Additional articles were searched using the following words as search terms: "working/employment/work activity/infection" in combination with "day care/child care/child day/ kindergarten/nursery" and with "pregnancy," "pregnancy/ 
reproductive outcome," "reproductive risk," "spontaneous/ threatened abortion," "miscarriages," "stillbirths," "fetal/ infant death," "embryonic/fetal/pregnancy loss," "perinatal death," "birth defects," "congenital malformations/defects/ anomalies," "low birth weight," "small/large for gestational age," "preterm/premature birth/delivery/labor," "postterm delivery," "sex ratio," "ratio of male/female births," and "offspring." Finally, some articles were identified from the reference lists of relevant articles.

\section{Eligibility criteria}

Article selection

Observational studies, such as cohort, case-control, and cross-sectional studies, as well as short communications focusing on pregnancy outcomes or occupational risks of infections in daycare, nursery and kindergarten staff, were included.

\section{Study population}

The exposed population had to be employed in daycare centers, kindergartens and nurseries, and clearly identified as female childcare providers. So, exposure was based on the job title within daycare settings. Most populations were pregnant women, with the exception of some research relating to occupational risks of infections (seroprevalence and seroconversion studies), in which all female daycare workers were included.

\section{Occupational risk estimates}

Only studies with reported risk estimates were retained: the ratio of observed to expected numbers of adverse issues $(\mathrm{O} / \mathrm{E})$, the relative risk $(\mathrm{RR})$, the odds ratio $(\mathrm{OR})$, the hazard ratio (HR), or the prevalence ratio (PR).

\section{Quality assessment}

Quality assessment of observational research was guided by the Strengthening and Reporting of Observational Studies in Epidemiology (STROBE) statement recom- mendations [11], a checklist of 22 items required to assess the studies' strengths and weaknesses. The items relate to the title, abstract, introduction, methods, results and funding sources. To be included in the overview, studies had to include at least 11 of the 22 items on the STROBE statement checklist.

\section{Exclusion criteria}

Factors other than work may affect the risk of adverse pregnancy outcomes [12]. These potential confounding factors are delivery age, infections and drug treatment during pregnancy, medical and obstetric history, smoking and drinking habits, education and family income, nutrition, etc. To minimize the risk of bias, these variables should be taken into account in statistical analyses whenever they are available. When factors related to mothers' medical history and lifestyle are not available, the selection of a comparison group may control these potential confounders [13].

Studies not including non-occupational variables or a comparison group were excluded, with the exception of descriptive studies relating to the risks of infections based on seroprevalence/seroconversion rates during endemic/ epidemic periods not requiring controls.

As the epidemiology of infectious risks differs between developed and developing countries, studies conducted in developing countries were also excluded [14].

\section{Summary of a literature overview}

The results presented in the studies reviewed are summarized in Tables 1, 2 and 3 listing the country of investigation, the study reference (first author, year), the study population, the type of study, the key adverse outcome(s), the occupational risk estimate, and comments on potential bias and weaknesses of the studies. Both authors examined these articles for items such as the study design, the study population, key outcomes, statistical analysis, covariates considered, and the quality of the study. 


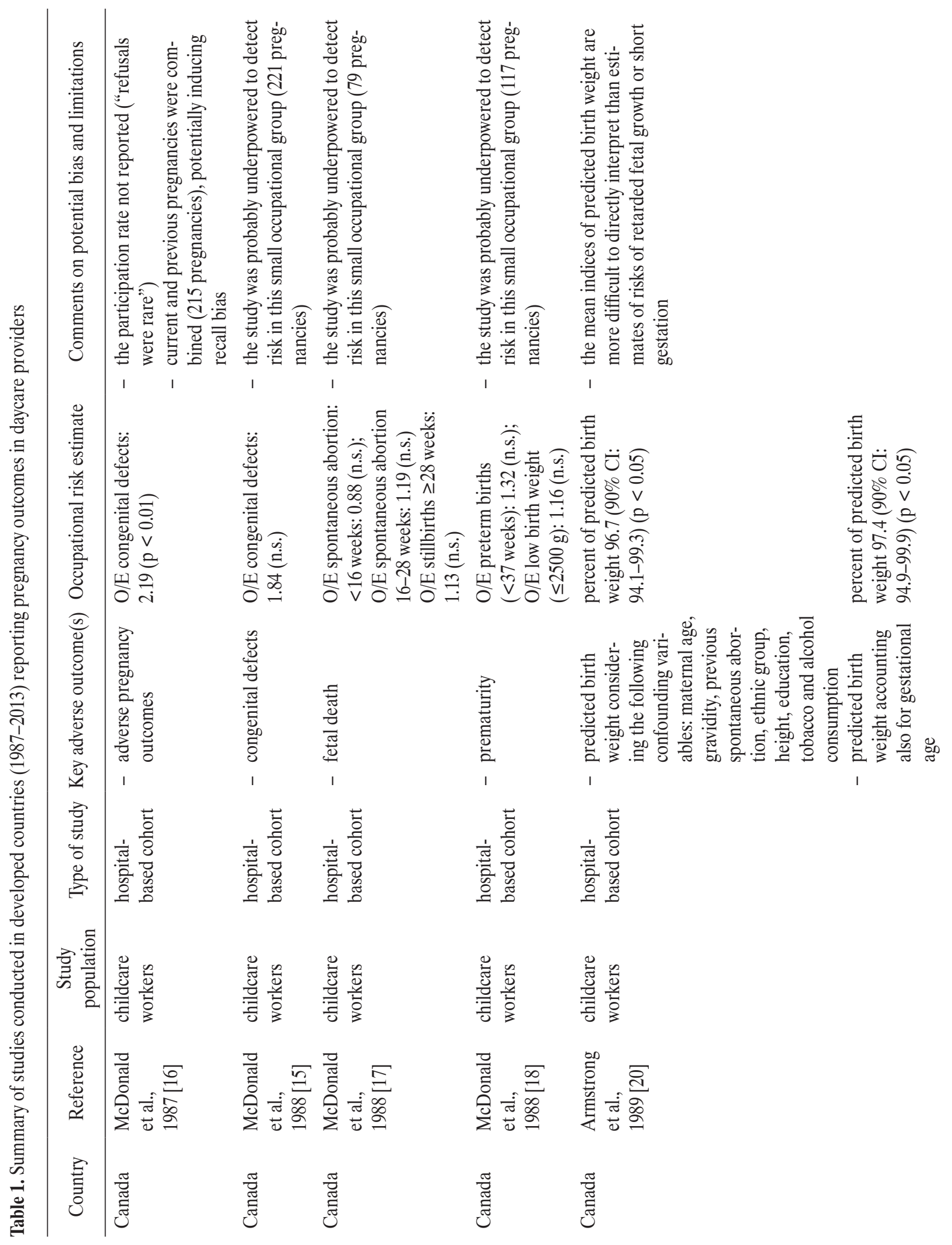



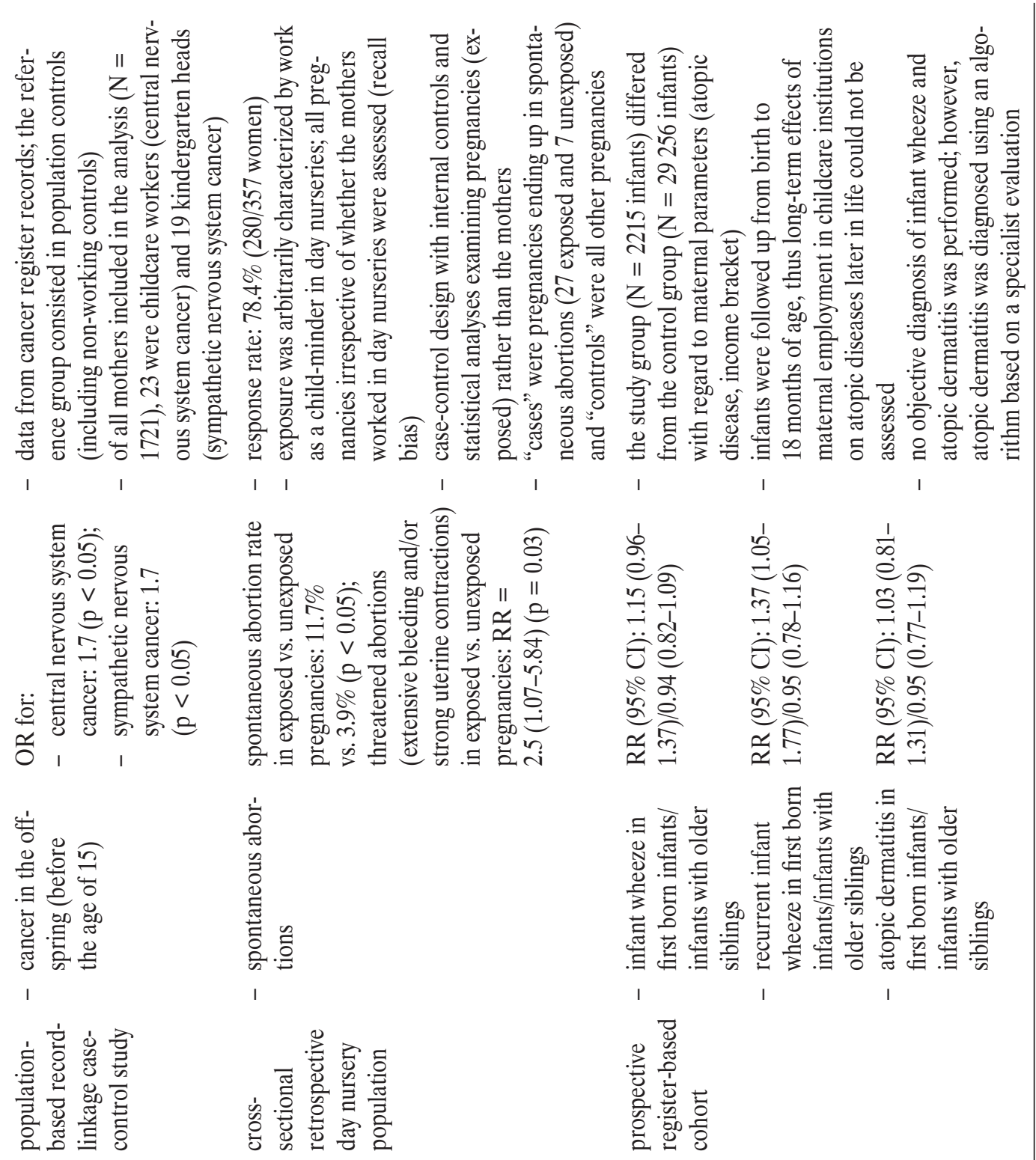

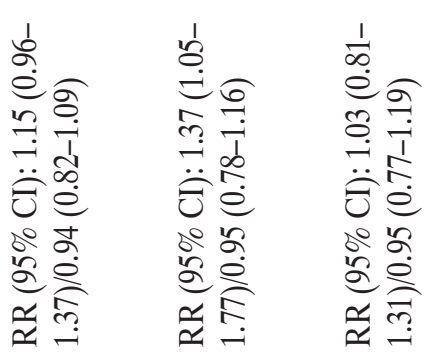
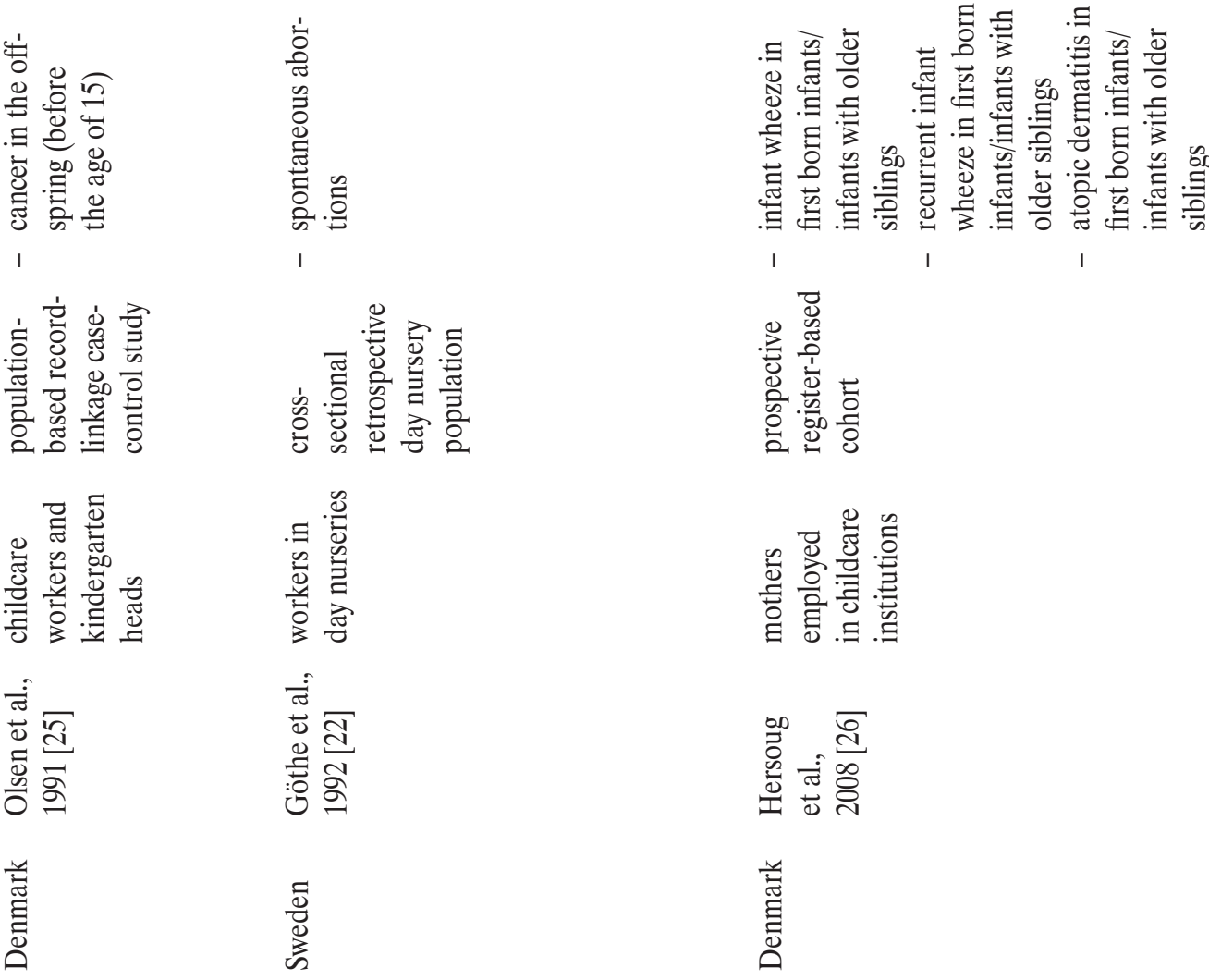

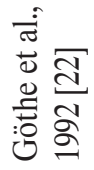

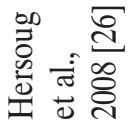

离

节 


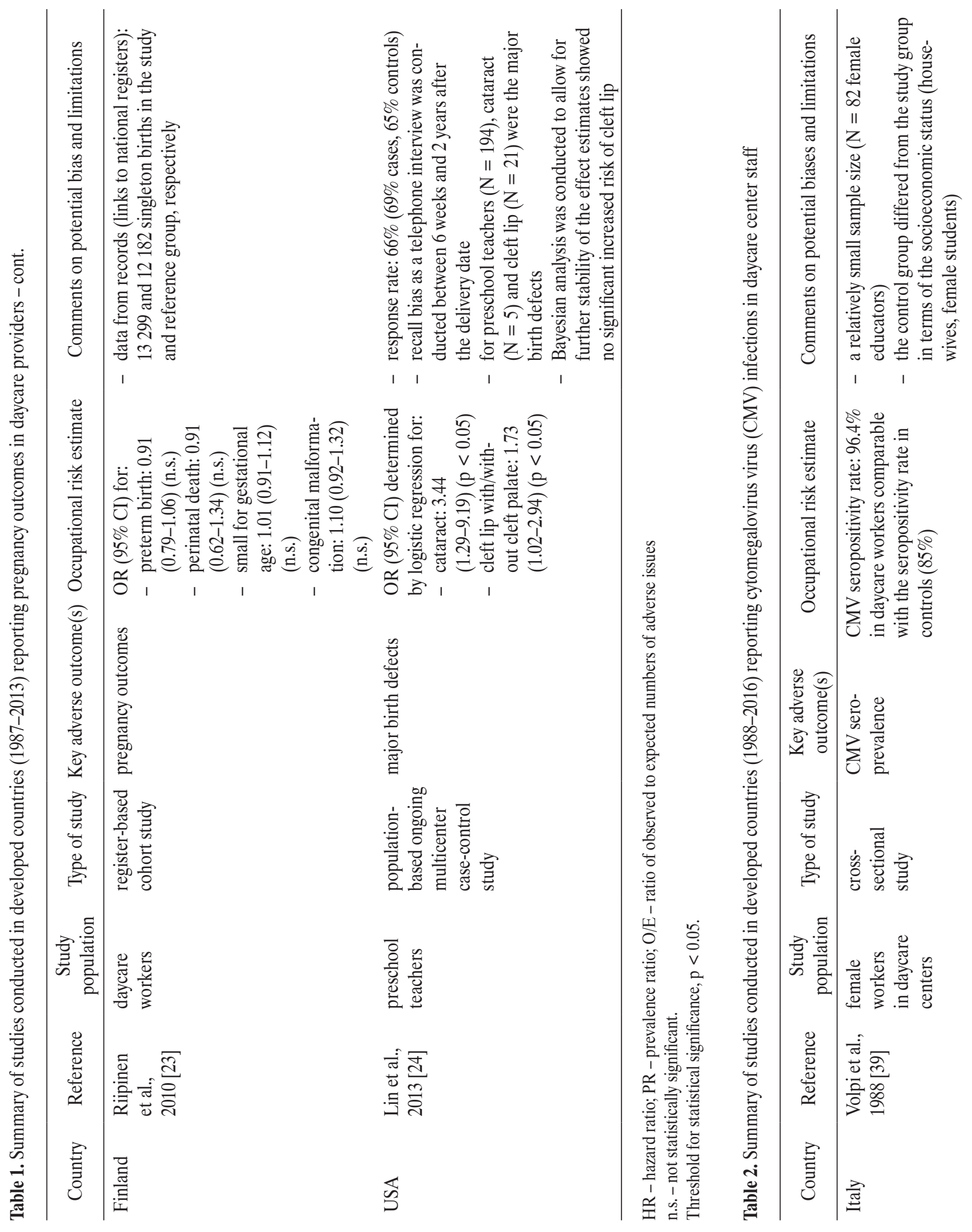



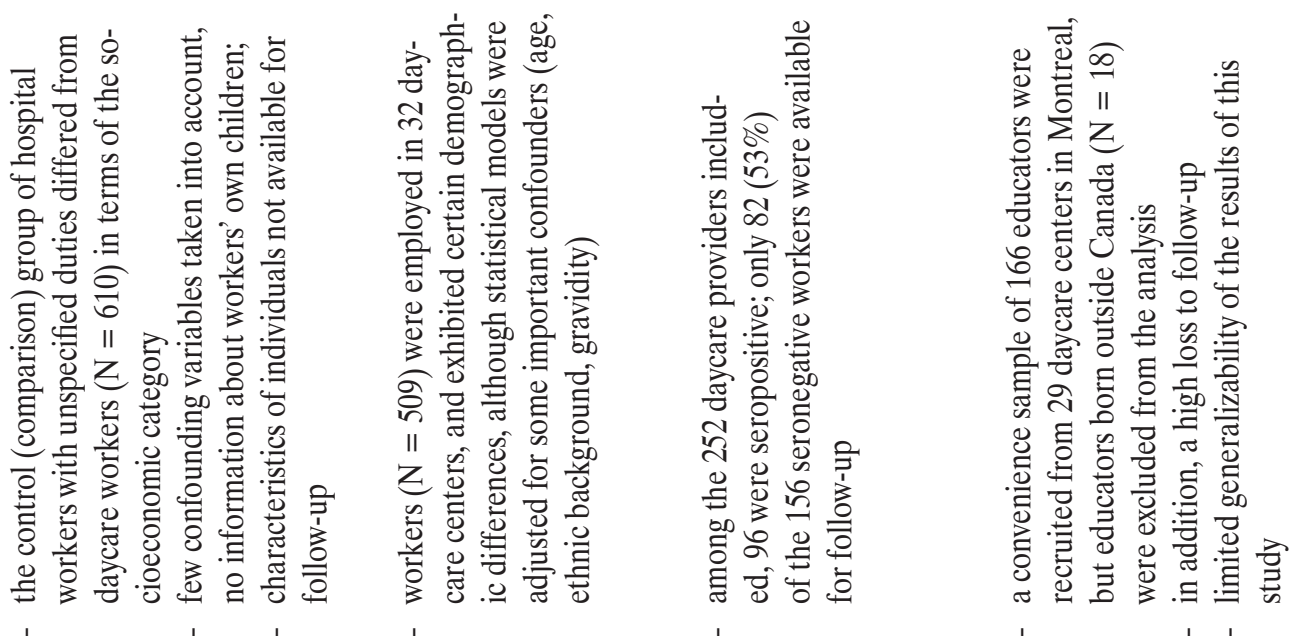

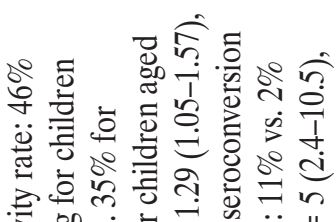
.

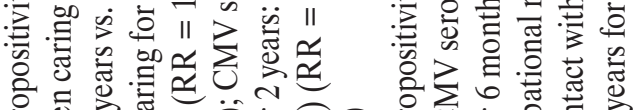

氙 㐫

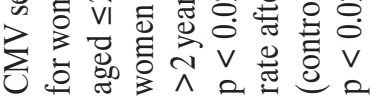

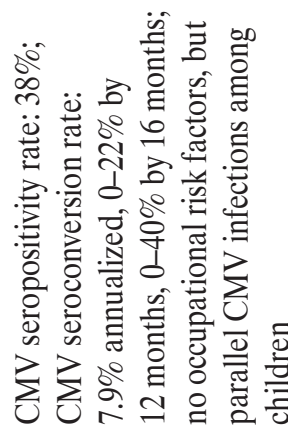

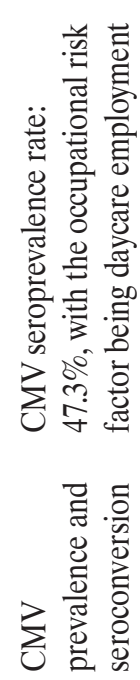

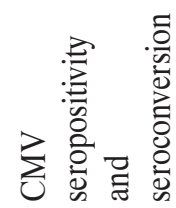

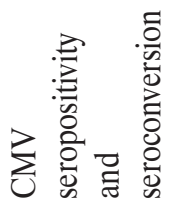

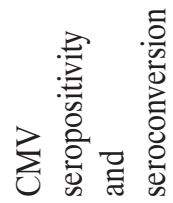

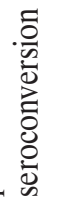

总

总

总

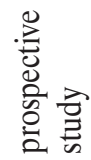

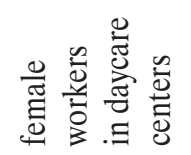

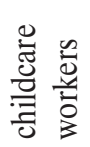

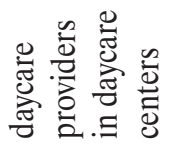

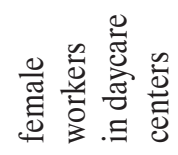

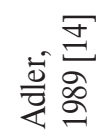

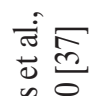

: ๙

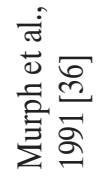

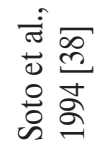

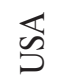

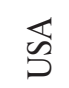

芯

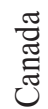




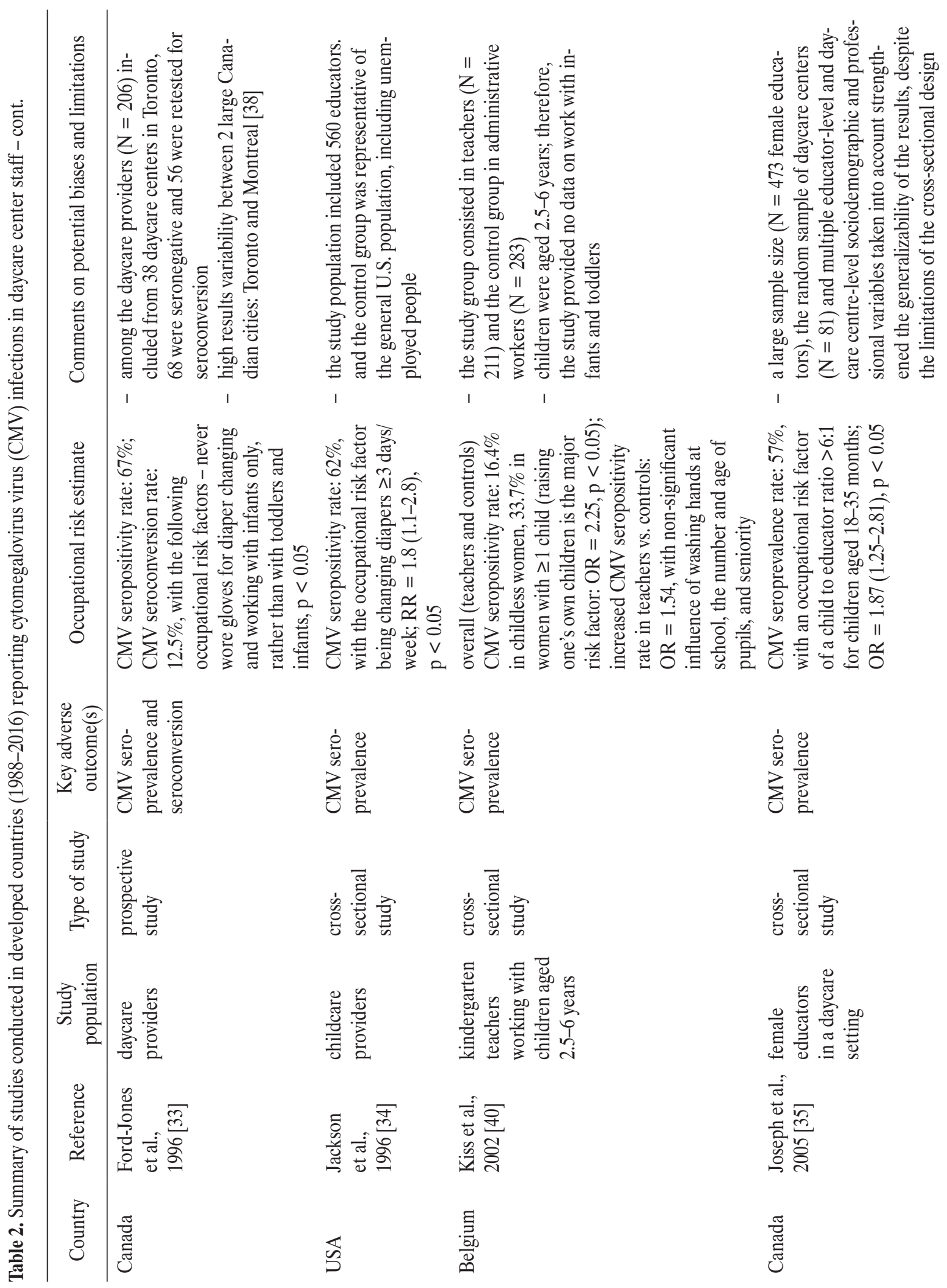



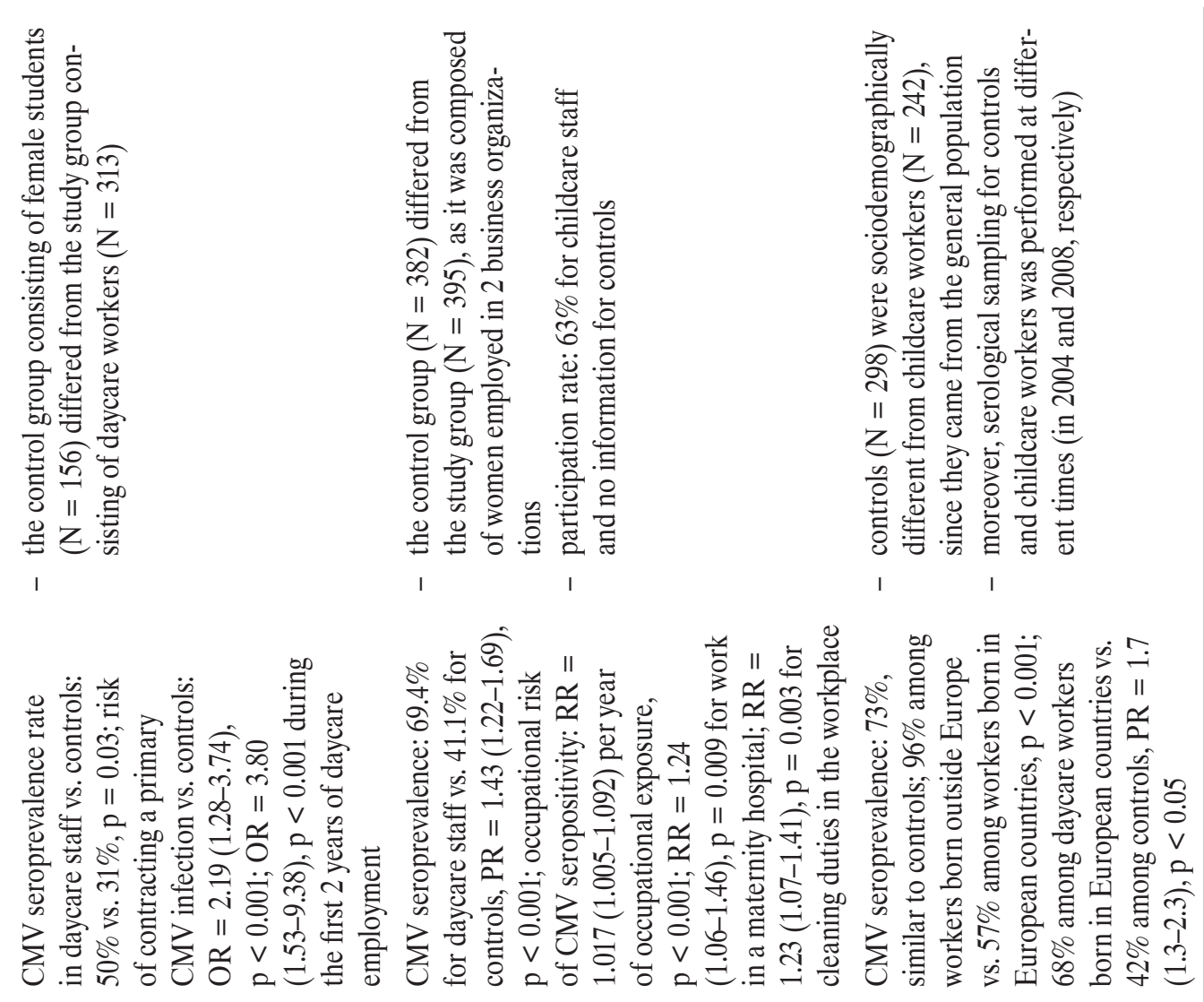

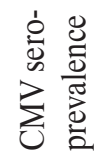

$\sum_{\substack{0 \\ 0}}^{\substack{0 \\ 0}}$

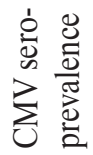

完总

恋

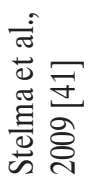

离壳

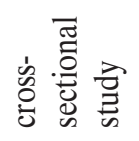

营

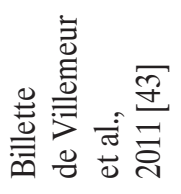

若
悹苐 总

壷

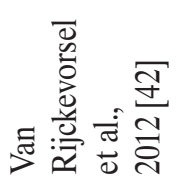

离 


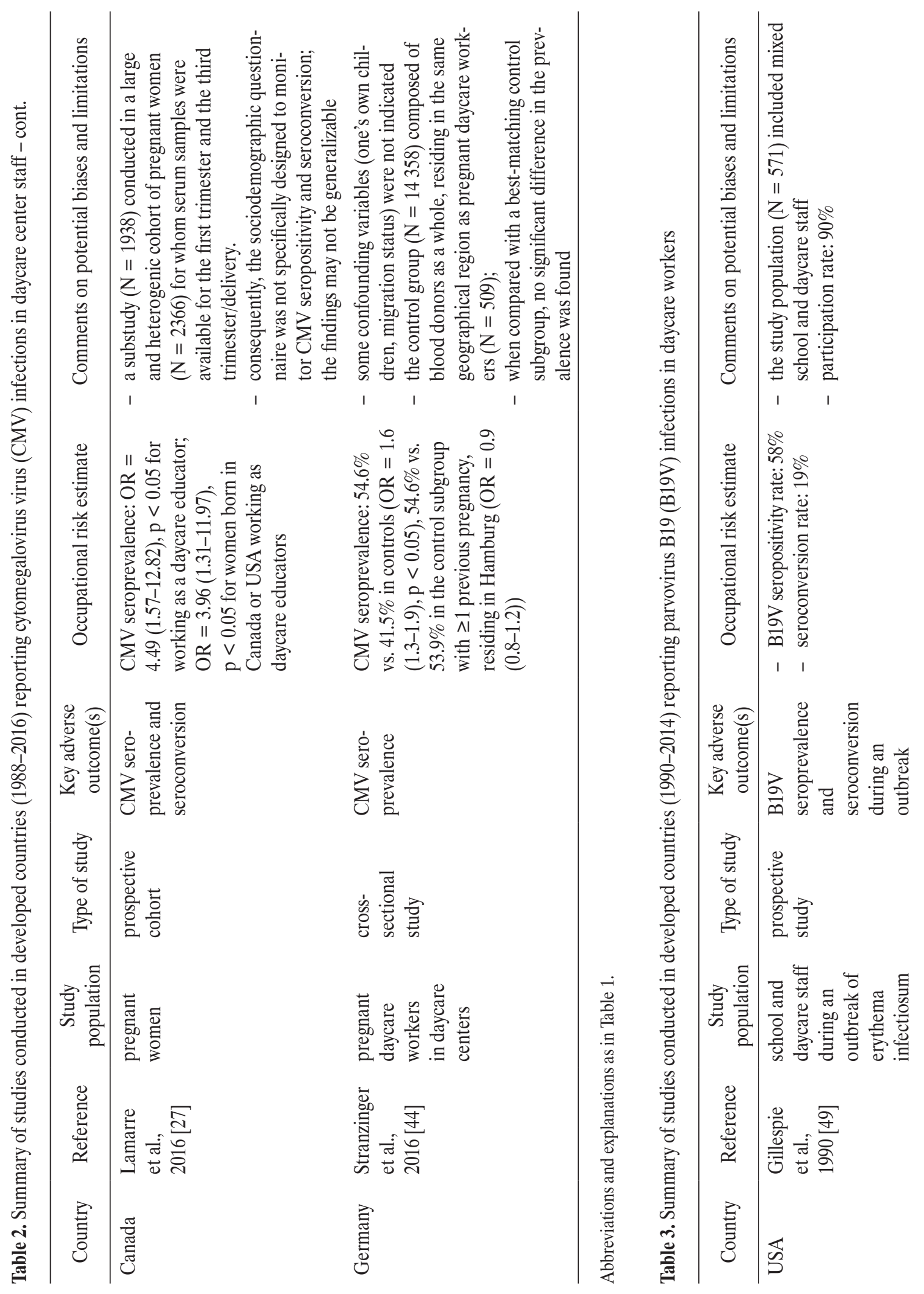



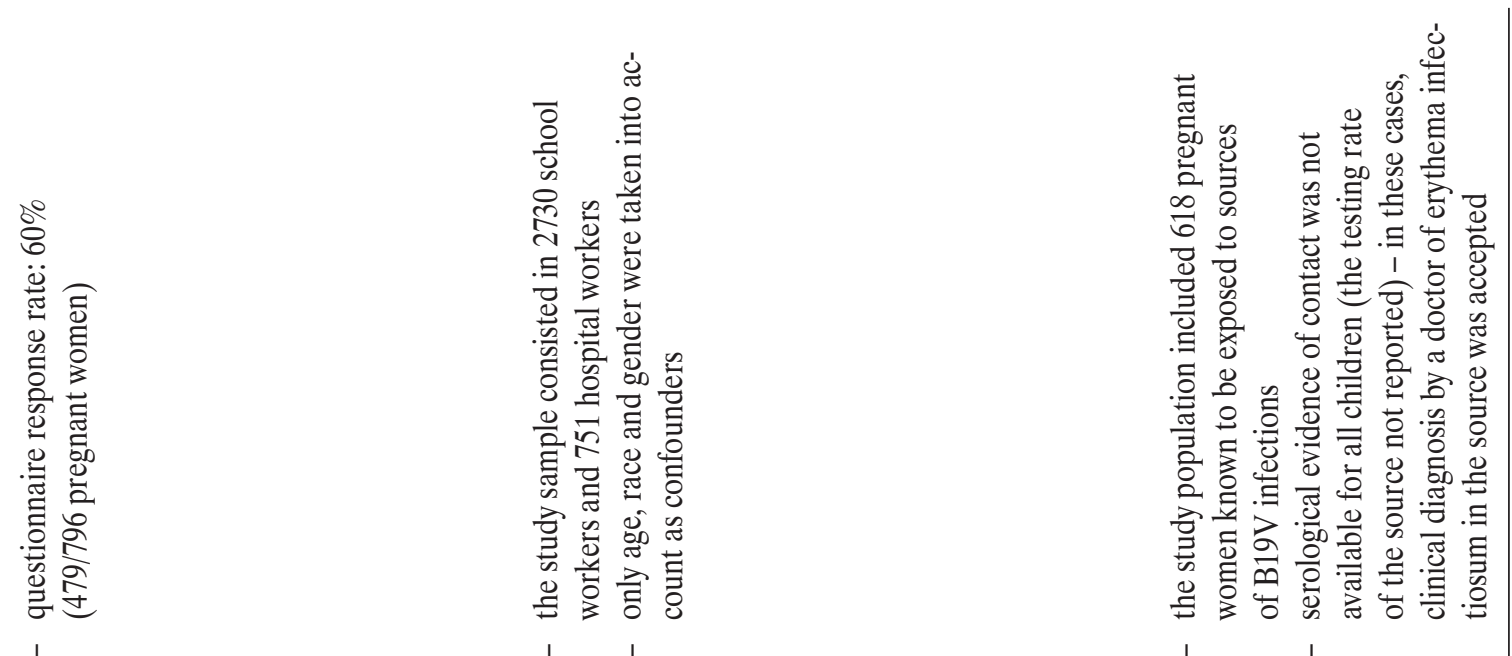

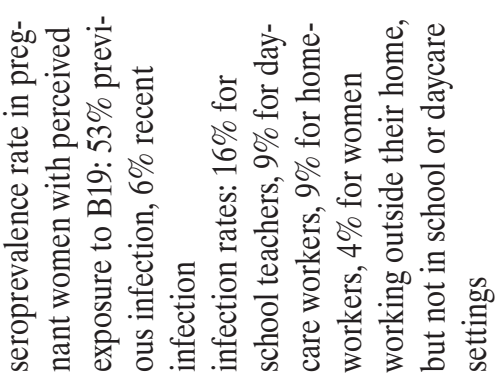

过完光"

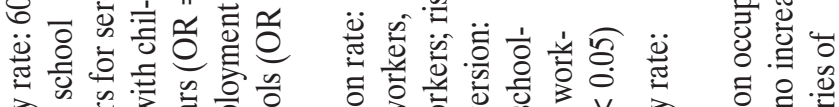

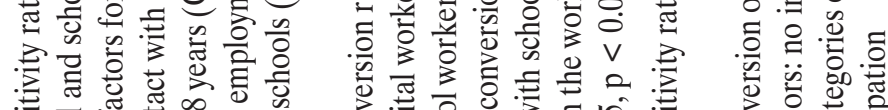

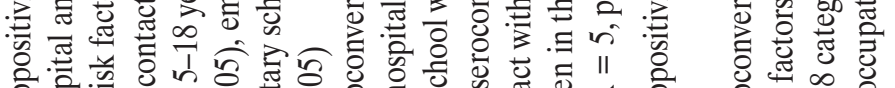

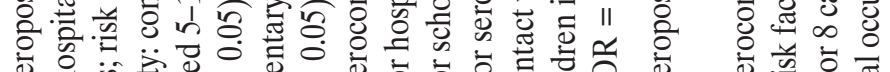

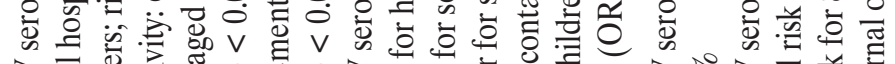

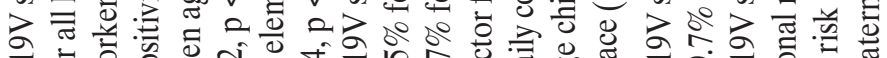

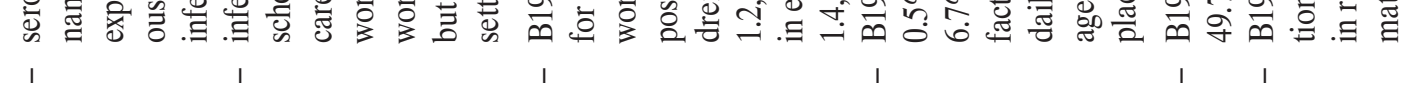

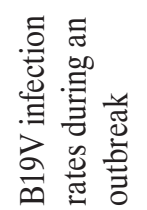

灾总

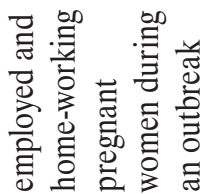

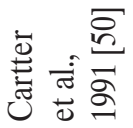

$\underset{D}{\overleftrightarrow{2}}$

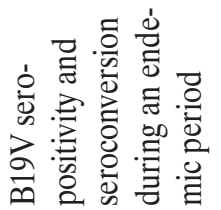

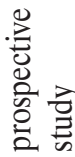

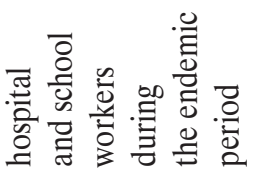

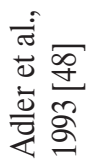

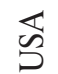

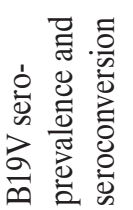

总
总吾
壳

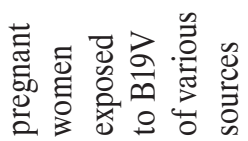

สं

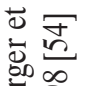

苂

芯 


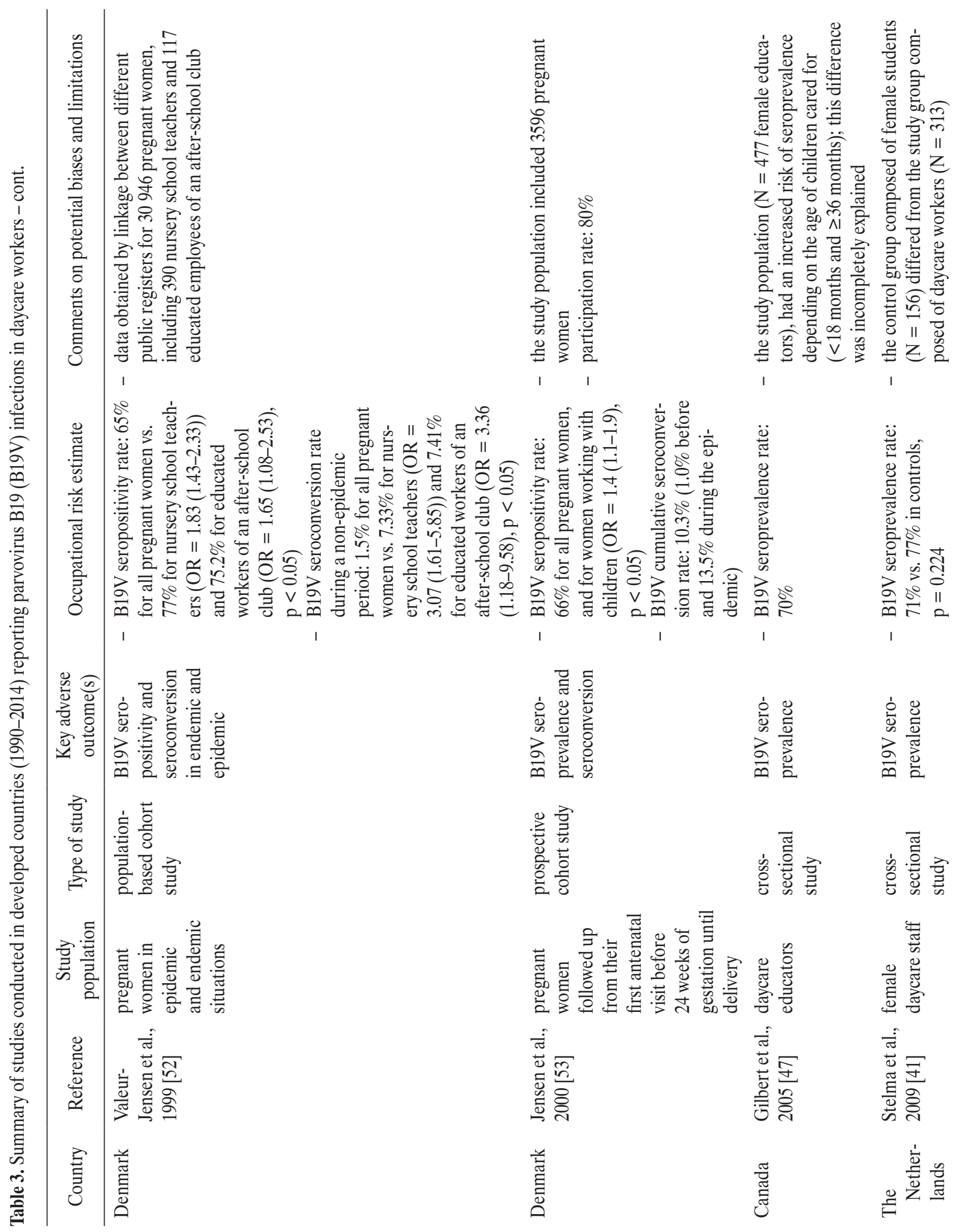



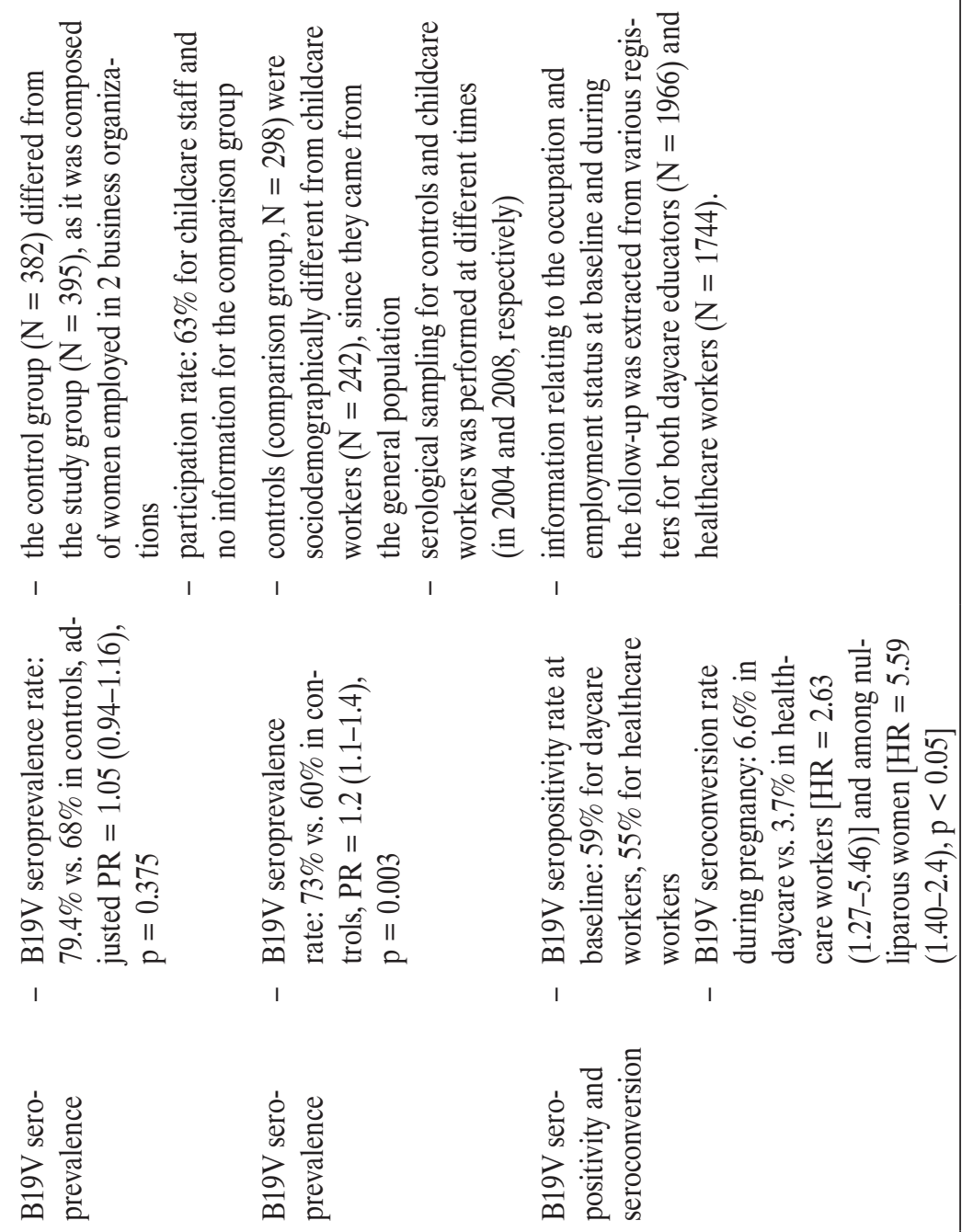

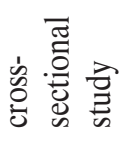
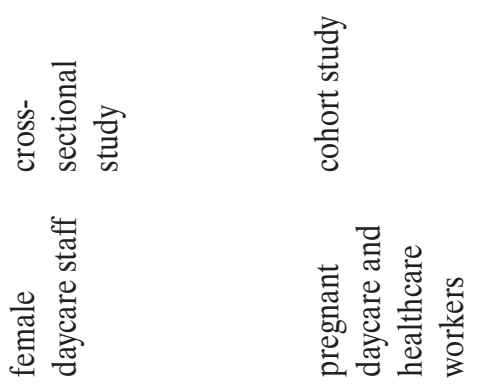

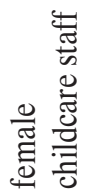<smiles>C1CCC(C2CCCC2)CC1</smiles>

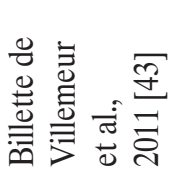

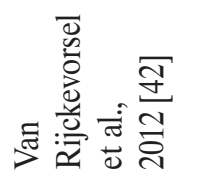

\section{:}

苛<smiles>C1CCC(C2CC2)C1</smiles>

营 


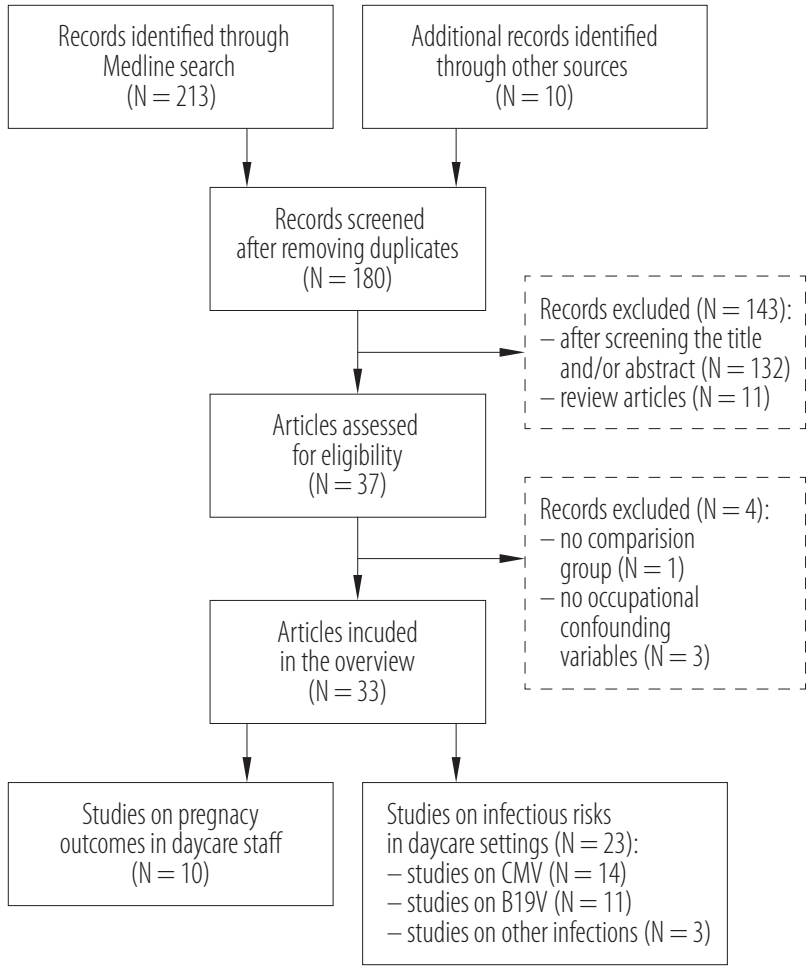

CMV - cytomegalovirus, B19V - parvovirus B19.

Articles were initially selected based on a literature search covering the period of 1980-2018. The remaining articles reported at least 11 of 22 STROBE statement items.

Figure 1. Studies included in and excluded from the review on pregnancy outcomes and infectious hazards related to employment in daycare settings

\section{RESULTS}

\section{Overview of literature search results}

The initial search of the database identified 223 records, 180 of which were selected to determine eligibility based on the study purpose and after removing duplicates. Figure 1 shows the flow diagram with numbers of articles identified and excluded at each selection step. Finally, 33 original studies were retained for the review: 10 studies related to pregnancy outcomes and 23 studies to infectious risks in daycare settings.

\section{Studies on pregnancy outcomes in daycare staff}

Literature reporting pregnancy issues in daycare workers is rather limited, and very few studies performed to date have included pregnant childcare staff as an occupational group (Table 1).

Studies conducted in the early 1980s in Canada focused on occupation and pregnancy outcomes over a 2-year period (56 067 women, 104649 pregnancies) and included childcare workers (6147 women, 221 pregnancies). Seven confounding variables (age, gravidity, pregnancy history-related variables, maternal education, smoking, alcohol consumption, ethnic group) were included in the models used to examine the association between work in the childcare sector and adverse pregnancy outcomes. Inconsistent associations between work in the childcare sector and congenital defects were reported $[15,16]$. No increase in the risk of fetal death [17], low birth weight $(\leq 2500 \mathrm{~g})$ or preterm birth ( $<37$ weeks) was found in this occupational group [18]. Nevertheless, workers in this sector were exposed to noise, heavy lifting and long work hours, all of which are known risk factors for prematurity and fetal growth retardation $[8,19]$. Because a reduced length of gestation is a cause of low birth weight, a closer reanalysis of birth weight data was adopted to permit gestational age to be taken into account [20]. The results showed that daycare workers were more likely to experience retarded fetal growth associated with lifting heavy weights $>15$ times/day and high fatigue indexes previously reported [21].

A study conducted in Sweden in the early 1990s showed that working in day nurseries was associated with higher spontaneous abortion and threatened abortion risks, but not with prematurity or congenital malformations [22]. In contrast, a Finnish study conducted in 2010 found no increase in the risk for adverse pregnancy outcomes among daycare workers [23]. More recently, a U.S. study found that preschool teachers had a 3-fold higher risk of giving birth to children with cataract and cleft lip with/without cleft palate [24].

An increased risk of childhood tumors of the central and sympathetic nervous system were reported in a Danish 
study examining the offspring of female childcare workers and kindergarten heads [25]. The authors pointed to infections during pregnancy as a potential risk factors for childhood cancer.

Finally, the possible protective effect of maternal microbial exposure at the time of conception and during pregnancy against infant wheeze and atopic dermatitis was not supported by the findings of a Danish study of mothers employed in childcare institutions [26].

In summary, studies evaluating the association between maternal daycare work and reproductive risks for pregnancy present inconstant results.

\section{Studies on infectious risks in daycare settings}

Although data reporting on problems in pregnancy are rare, literature pertaining to infectious risks in daycare settings is extensive.

\section{Cytomegalovirus}

Primary maternal infections with CMV during pregnancy result in viral transmissions to the fetus in up to $40 \%$ of cases [27]. In contrast, only $1 \%$ of CMV immune mothers who were already infected before pregnancy transmit the virus to the fetus, more often by reinfection than by reactivation of the latent virus [28]. Overall, about $10 \%$ of congenitally infected newborns have long-term sequelae, with the most frequent being hearing loss (50-59\%), mental retardation (47-55\%), cerebral palsy (49\%), seizures (11-23\%) and visual impairment (10-20\%) [29,30]. Between 1-2\% of seronegative women may contract a primary CMV infection during pregnancy, and seronegative women at high risk include daycare workers, who have a 10-20\% annual infection rate [31]. Seroprevalence in adulthood may vary even between developed countries, and the occupational risk of contracting CMV in daycare centers varies accordingly [32]. Most CMV seroprevalence and seroconversion studies in daycare educators were performed in North America in the 1990s (Table 2). Serop- revalence in this occupational group is $<70 \%(40-67 \%)$ in Canada and the USA [14,33-38], but $>85 \%$ in Italy [39], which is similar to the seroprevalence for the Italian general population. The annual seroconversion rates in seronegative daycare educators were rather high in the USA and Canada (10-20\%), whereas, in contrast, there is no evidence to suggest that CMV infection is a potential problem in British daycare settings [29].

North American daycare workers were shown to be at risk of CMV infections related to their work in daycare settings, and related to personal risk factors like older age, non-white race, foreign birth, birth in a low- or middleincome country, having children at home ( $\geq 2$ children of their own, in particular children aged $<5$ years), living with $\geq 4$ people, or having left school before the age of 15 .

The daycare-specific risk factors for CMV seropositivity and seroconversion, as shown in Table 2 (caring for $>6$ children and for children aged $<2-3$ years, changing diapers $\geq 3$ times/week, not wearing gloves when changing diapers, employment in the daycare sector for $>5$ years), suggest that educators are at an increased risk of acquiring CMV from children in daycare settings. Indeed, infants shed viruses more often than toddlers ( $21 \%$ vs. $8 \%$, average: $17 \%$ ) [33], and viral DNA patterns were in most cases identical among children and workers who shed isolates of CMV in saliva or urine [14]. Moreover, poor hygiene practices and new CMV shedding in children were associated with a higher infection rate in daycare workers $(0-22 \%$ by 12 months, average: 7.9\%) [36]. However, a Belgian study conducted among kindergarten teachers found that washing hands at work, the number and age of school children, and the length of employment did not significantly influence seropositivity, while parenting their own children was the major risk factor for CMV seropositivity in this population [40]. Indeed, the CMV infection rate is $47 \%$ for parents of a CMV-shedding child aged 0-12 months, and $32 \%$ if the child is $\leq 18$ months of age, compared to $7.9-20 \%$ in daycare workers [28]. 
Studies conducted in European countries showed a positive association between employment in daycare centers and CMV infections [41-43]. In the Netherlands, female daycare staff were at an increased occupational risk of a primary CMV infection, especially during the first 2 years of employment [41]. Having $\geq 1$ child of their own, and having children in daycare or at school, did not correlate with CMV seroprevalence in adjusted models, whereas work seniority was associated only for the first 2 years of employment in the daycare sector. In another study conducted in the Netherlands, CMV seroprevalence was strongly related to the country of birth and was much higher among non-European women born in Africa, Asia, South or Central America [42]. Consequently, for daycare workers of European origin only, the CMV infection was associated with their workplace (the seroprevalence ratio $=1.7$ ), and, in the same subgroup, with raising $\geq 1$ own child (the seroprevalence ratio $=1.2$ ).

French female childcare staff had an increased occupational risk of contracting CMV infections compared to a reference group (the seroprevalence ratio $=1.43$ ) [43] . Notably, CMV seroprevalence increased with the duration of contact with children in the workplace, for workers performing cleaning tasks in childcare centers and for those who had previously worked in maternity hospitals, and was marginally higher in full-time childcare staff compared to drop-in childcare staff. However, the risk was not associated with the number of children cared for. Childless women or mothers of a single child had a higher risk of an occupation-related CMV infection compared to those who had $\geq 2$ children of their own. Overall, the risk attributed to occupation was $30 \%$ for childcare staff, and a similar risk was calculated for some personal risk factors (the number of one's own children, in-home care for one's own child, one's own children attending a childcare facility, exposure through one's spouse) which ranged 14.5-32.4\%.

Only 2 studies reported on pregnant women. In a cohort of 1938 pregnant women in the province of Quebec,
Canada, $58 \%$ of the subjects were seronegative during the first trimester of pregnancy, which placed them at risk of a primary CMV infection [27]. Higher seroprevalence was significantly more frequent in mothers working as daycare educators, but other factors were associated with previous CMV infections, such as having $\geq 1$ child of their own, a low socioeconomic status, being born outside Canada or the USA, and having a first language other than French or English. The annual CMV seroconversion rate was 5.1\% (95\% CI: 3.2-7.7) and was not associated with any specific study population characteristics. In the region of Hamburg, Germany, the prevalence of anti-CMV IgG was significantly higher among pregnant daycare workers compared to female blood donors as a whole $(55 \%$ vs. $42 \%$ ) across all age groups. However, when compared to the subgroup of female blood donors matching best, based on past pregnancies and living in the city of Hamburg, the seroprevalence rates were similar among pregnant daycare workers and controls (54.6\% vs. 53.9\%) [44]. In summary, these findings suggest that employment in daycare facilities in developed countries is associated with an increased risk of CMV infections, although $>30 \%$ of women remain seronegative and at risk of a primary infection during pregnancy. The main occupational risk factors are related to the high number and young age of children cared for, to changing diapers, to not using gloves, and to work seniority. The risk of seropositivity attributed to personal factors (older age, foreign birth, raising one's own children) is similar to, or even greater than, the occupational risk. Therefore, younger childless women employed in daycare centers are at the greatest risk for contracting a primary CMV infection during pregnancy, which raises concerns related to a vertical transmission of CMV and clinical outcomes of congenital infections.

\section{Parvovirus B19}

Parvovirus B19 infects 1-5\% of pregnant women, and the transplacental transmission of $\mathrm{B} 19 \mathrm{~V}$ occurring in 
25-33\% of them may cause fetal loss or fetal damage, such as severe anemia, cardiac failure or brain anomalies [41,45]. In Europe, B19V-related fetal loss is underreported, and the occupational risk in pregnant women has yet to be fully addressed. For instance, in Northern Ireland, only $5 \%$ of the fetuses lost were tested for B19V, and only $52 \%$ of pregnancies were checked following occupational exposure to erythema infectiosum, mainly among teachers or daycare workers [46].

The authors identified 11 studies investigating the occupational risk of B19V infections in daycare staff (Table 3). The association between employment in daycare centers and B19V seropositivity was reported in some [42,47-49] but not in all studies [41,43]. Unlike CMV, B19V seropositivity does not seem to be linked to ethnic background. In a Dutch study, B19V seropositivity was independently associated with employment in daycare centers and with having one's own children, but not with the country of birth [42]. The risk of infection was high for pregnant women exposed during epidemics, and was associated with contact with children. During an outbreak of erythema infectiosum in Connecticut, 1 study reported a high infection rate with B19V for pregnant school teachers (16\%), daycare workers (9\%), and homemakers (9\%), whereas women employed in other occupations outside their home had the lowest rate (4\%) [50].

A cohort study compared B19V infections in pregnant daycare workers and healthcare workers with no occupational contact with children during a B19V epidemic in Finland [51]. A 3-fold increase in the risk was observed among daycare workers compared to women employed in healthcare, and the association was stronger among nulliparous women. Actually, the risk of seropositivity increased in relation to the number of one's own children $(\geq 3)$ but was unrelated to age or job seniority. Similarly, in Denmark, pregnant nursery school teachers were at an increased risk of an acute infection compared to other pregnant women, but the population-attributable risk of seroconversion was $55.4 \%$ for having one's own children and only $6 \%$ for occupational exposure to children [52], suggesting that most infections during pregnancy result from exposure through the woman's own children. The independent determinants for past infections were personal factors (an increased number of siblings, having siblings of similar age, the number of one's own children) and occupational exposure to children aged $<7$ years (nursery school teachers) or children aged 7-16 years (after-school clubs).

During a large B19V epidemic in Denmark, another study found no increase in the risk of an acute B19 infection during pregnancy among women working with children, but a trend for a higher prevalence of B19 IgG seropositivity was observed at the first antenatal visit among women working with children compared to women in other professions [53]. The higher level of immunity among women employed in this sector might explain the abovementioned negative association. In all pregnant women combined, B19V infections during pregnancy were significantly associated with adverse pregnancy events (a 10-fold increase in late spontaneous abortions and stillbirths). Independent risk factors related to the increased risk of $\mathrm{B} 19 \mathrm{~V}$ infections during pregnancy were having children at home, suffering from a serious medical condition, and having a stressful job.

In the USA, during an endemic period, seropositivity for pregnant women in contact with cases of erythema infectiosum correlated weakly with employment as elementary school teachers (41 of 76 were immune) and as daycare workers (25 of 42 were immune) [48]. The risk of contracting B19 infections in seronegative elementary school teachers $(23 \%)$ or seronegative daycare workers $(24 \%)$ was somewhat higher than the overall $16.7 \%$ infection rate, but the difference was not statistically significant. A previous study conducted among pregnant women exposed to B19V found no increase in the risk of infections in 8 categories of maternal occupations involving contact 
with children, but it did report a 3-fold higher risk if their own children were the source of infection [54].

Older studies showed that, among school and daycare staff, 58\% had evidence of past infections, and 19\% contracted a B19V infection during a large outbreak of erythema infectiosum in Connecticut [49]. The risk of seroconversion was increased for teachers and daycare providers in contact with a larger number of ill children, and with younger children.

In Montreal, B19V seroprevalence among daycare educators was $70 \%$ [47]. In daycare educators aged $<40$ years, a significant association with the length of employment in daycare centers was found. The risk of being seropositive depended on the age of children cared for, and was increased in educators in charge of children aged $<18$ months or $\geq 36$ months compared to those working with children aged 18-36 months.

In summary, daycare workers exhibit a high rate of B19V seropositivity which is also related to personal factors less to ethnic background than CMV, but strongly linked to having their own children and their number. The risk of seroconversion during an outbreak is thus mainly of concern among nulliparous younger daycare workers who are in contact with larger numbers of ill children and with younger children. This exposure is of greater concern as fetal loss due to a B19V infection seems to be underreported.

\section{Other infectious risks}

Very high rates of seroprevalence to rubella (98.7\%) and varicella $(100 \%)$ were observed in childcare staff and reference groups in France [43] and the Netherlands [42], and no occupational risks were found. In 2001, in Montreal, an overall seronegativity of $10.2 \%$ for rubella was found [55], and the most important predictors of rubella seronegativity for daycare educators were younger age, the lack of rubella vaccination and not having their own children.

\section{Final remarks and practical implications}

\section{for workers' health protection}

This review of the available data suggests that daycare workers are faced with inconsistent reproductive risks for pregnancy problems including spontaneous abortion and congenital malformations. These risks are probably related to infectious agents excreted by children. In addition, a risk of retarded fetal growth could be related to physical constraints. Overall, women working in daycare settings have an increased risk of contracting $\mathrm{CMV}$ and $\mathrm{B} 19 \mathrm{~V}$ infections compared to reference groups, but personal characteristics are also independent determinants of seroprevalence and seroconversion in this occupational group.

\section{Potential bias and limitations of the studies}

Recall bias and low response rates were common among the studies, hinting that some bias may be present. Small study populations, particularly small numbers of exposed cases despite relatively large samples, justify multicenter studies to avoid underpowered epidemiological studies. Potential confounding non-occupational variables should be included when interpreting data such as the socioeconomic status, education, residence, family income, country of birth, delivery age, reproductive history, prenatal care, weight gain during pregnancy, nutrition, smoking, drinking, drugs consumption, etc. [56]. Unfortunately, confounding factors related to lifestyle and health are not available in historical cohort studies or birth certificates. Appropriate comparison groups should be used to control for confounding bias, but reproductive health should not be compared between employed vs. non-employed mothers. Thus, studies in which unexposed groups including employed women with comparable or similar occupations were used as comparison populations are less likely to be biased than where comparison groups included non-employed women or women with different occupations [13]. The relevant time window of exposure must be considered when examining pregnancy outcomes. Generally, the criti- 
cal vulnerability window extends before and during pregnancy, from approximately 1 month before conception, and covers both the pregnancy and the breastfeeding periods. The most vulnerable period of fetal and newborn development is the first trimester, although some effects have been observed in the second and third trimesters. For instance, B19V may cause fetal loss especially in the second half of pregnancy, when other causes of fetal loss are rare [45].

The identification of pregnancy outcomes can be achieved from a variety of sources, such as birth certificates, death certificates, medical records, postal or interviewed questionnaires with parents, surveillance systems like registries, or health surveillance programs. Compared to the data collected by means of questionnaires, medical records and hospital information based on medical diagnoses and recordings at the time of the event afford more sound data [57].

The exposure assessment is an essential problem in occupational studies. In this overview, exposure was simply defined as being employed in a childcare setting and being identified as a childcare provider. Actually, the paucity of the research involving this occupational group did not allow for analyzing specific risk factors.

To avoid biases in future studies, prospective cohorts must be suitably designed to include a large-scale population and a narrow recall period, to improve the estimation of occupational exposures and the quality of outcome assessments, and to collect the potential confounding variables.

\section{Preventing infections within childcare centers}

Generally, 4 categories of preventive measures can be applied to prevent transmission of infections within a childcare center, i.e., antimicrobial treatment and/or prophylaxis; exclusion or quarantine of ill or infected children; infection prevention through age-appropriate immunization of both staff and children; and environmental controls with regard to hand hygiene, diaper changing practices, surfaces cleaning, or handling food [5]. Moreover, formal written policies for infection control within childcare and repeated training for staff to prevent transmission of infections should be implemented.

The epidemiology of infections within daycare centers is driven by person-to-person contact, which is common and expected in these settings. Because CMV is transmitted during close contact with child's infected secretions and excretions, good personal hygiene should be practiced, especially by hand-washing after activities such as feeding, bathing, wiping drool or runny nose, or handling child's toys. To reduce the risk of infections, good hand hygiene should be applied to both the staff and children. Hands are best washed in warm, soapy water after removing rings and other jewelry. Alcohol-based hand rubs (hand sanitizers) appear safe to use among children and staff in daycare centers, since no evidence of elevated alcohol concentrations in alcometer readings for children were reported [58].

Diaper changing surfaces should be clearly separated from the food preparation area. Moreover, as much as possible, staff members who care for children using diapers should not be involved in food preparation [5]. Diaper changing surfaces should be non-porous and cleaned with a disinfectant after each change, together with other work surfaces that come in contact with urine or saliva, like toys or countertops.

Exposure to saliva allows direct transfer of the virus to mucous membranes. A simple surgical mask provides equivalent protection against exposure to saliva to an N95 mask, and is associated with better compliance as it does not cause skin irritation [59]. As a reminder, an N95 respirator is a respiratory protective device designed to achieve a very close facial fit and very efficient filtration of airborne particles (the "N95" designation means that when subjected to careful testing, the respirator blocks $\geq 95 \%$ of very small $[0.3 \mu \mathrm{m}]$ test particles).

Protective gloves should be worn during diaper changes and when manipulating children's unclean laundry. 
Additional hygiene practices such as avoiding intimate contact with the child through kissing, on or near the mouth, sleeping together, sharing towels, washcloths and toothbrushes, and sharing food, drink, cups and plates can also reduce risk of CMV infection.

In summary, CMV transmission can be reduced by avoiding contact with children's excretions and secretions, restricting close contacts with children and washing hands both frequently and regularly.

\section{Protection of pregnant workers}

A pregnancy intention status is an important determinant of pregnancy-related health behavior and should be considered in prenatal programs. Women should be made aware that unplanned pregnancies are more likely to involve exposure to harmful occupational hazards during the critical vulnerability window for pregnancy outcome.

Daycare workers planning a pregnancy may need to be screened for the CMV status before conception. For seronegative workers, hygienic practices to reduce the risk of CMV infection, as washing hands after diaper changes and contact with respiratory secretions, is strongly recommended [30]. Hand-washing, using gloves, and restricting close contacts were successfully used to reduce CMV transmission to pregnant caregivers.

Regulations to reduce contamination levels and to protect women of childbearing age in occupational settings differ between countries and periods. In Germany, daycare providers have implemented working restrictions for pregnant CMV seronegative daycare workers, such as exclusion from professional activities with children aged $<3$ years [44].

It must be emphasized that there is currently no vaccine available for CMV and parvovirus infections. In contrast, vaccination should be strongly encouraged for women employed in the childcare sector who are not immunized against varicella or rubella [43], although immunization with live virus vaccines during pregnancy is not recom- mended because of the risk of possible vertical transmission. For pregnant childcare staff, guidelines and recommendations relating to infectious diseases, stress and physical requirements have been reviewed elsewhere [6]. Ensuring, when available, age-appropriate vaccination of children and staff in childcare facilities, along with optimal ratios of children to caregivers, represent proven beneficial interventions to reduce infections [5]. It should, nevertheless, be noted that protection against infections does not eliminate other occupational risks for adverse pregnancy outcomes not addressed in this work, such as physical efforts and job stress for daycare providers.

\section{Dealing with sick children}

Updated guidelines on how to manage infectious diseases in childcare and schools provide the staff of childcare facilities with clear and easy-to-use information on the prevention and management of infectious diseases in daycare settings [60]. Childcare centers may thus provide care to healthy and mildly ill children. Sick children may be cared for within larger daycare centers or might be based in a separate facility specifically designed for mildly ill children who are ruled out from systematic childcare activities.

Exclusion as a means of reducing cross-infections has a limited effect as the shedding of infectious agents often precedes an illness and may persist for some time after its symptoms have resolved [5]. In addition, alternative care options for ill children may not always be available, or may be considerably more expensive. Nevertheless, when a child's illness restrains the child from participating in regular activities or requires a level of care that might be detrimental to the other childcare center attendees, an alternative mode of care outside the center appears appropriate. Moreover, certain symptoms displayed by a child, such as high fever, lethargy, difficulty breathing, rash with fever, repeated vomiting, increased production of infectious materials (diarrhea, drooling, conjunctivitis), etc., could be indications that the child has a serious sick- 
ness or the likelihood of secondary transmission of infectious agents, requiring a level of observation not possible in a daycare center.

Specific diseases necessitating exclusion from a daycare facility and the duration of exclusion should be clearly guided by childcare centers policies. Immunocompetent children with B19V or CMV infections do not usually need to be excluded, all the more so CMV is generally clinically quiet in healthy children [28]. Compliance with daycare center policies tends to improve when written policies are individualized for each center [5], and communication between daycare providers and parents is an essential part of promoting these policies. Well-educated parents are thus less likely to bring ill children into the center, and information obtained from the parents (e.g., on how the weekend went) can help the staff to identify a possible problem.

\section{CONCLUSIONS}

Working in a daycare setting presents rare and inconsistent risks of adverse pregnancy outcomes. Few studies included the occupational group of daycare providers or tackled the risks for pregnancy in women of childbearing age.

Viral infections represent the most common risk for pregnancy issues in daycare centers. Workers generally exhibit a high rate of past infections, which is also strongly related to personal factors. Among daycare staff, young nulliparous women remain sensitive to infections and are at an increased risk of seroconversion during pregnancy.

Unplanned pregnancies are at a greater risk of exposure to occupational hazards.

Knowledge about the effects of infections, serological screening and monitoring during pregnancy could protect seronegative women from exposure and primary infections.

Vaccination, if applicable, and interventions to educate staff on hygiene measures in the workplace offer the best protection and represent easy-to-implement broad primary prevention strategies for women of childbearing age.

\section{ACKNOWLEDGMENTS}

The authors would like to thank M. Guy Hédelin, INRS- Head of the Department of Epidemiology, for his valuable supervision.

\section{REFERENCES}

1. Russell H, Banks J. Pregnancy and Employment: A literature review. Crisis pregnancy programme. HSE Crisis Pregnancy Programme and the Equality Authority; 2011.

2. World Health Organization. The 2017 update, Global Health Workforce Statistics. Geneva: The Organization; 2017.

3. Quansah R, Jaakkola JJ. Occupational exposures and adverse pregnancy outcomes among nurses: a systematic review and meta-analysis. J Womens Health (Larchmt). 2010; 19(10):1851-62, https://doi.org/10.1089/jwh.2009.1876.

4. Warembourg C, Cordier S, Garlantezec R. An update systematic review of fetal death, congenital anomalies, and fertility disorders among health care workers. Am J Ind Med. 2017;60(6):578-90, https://doi.org/10.1002/ajim.22711.

5. Brady MT. Infectious disease in pediatric out-of-home child care. Am J Infect Control. 2005;33(5):276-85, https://doi. org/10.1016/j.ajic.2004.11.007.

6. Gratz RR, Boulton P. Health considerations for pregnant child care staff. J Pediatr Health Care. 1994;8(1):18-26.

7. Adler SP. Screening for cytomegalovirus during pregnancy. Infect Dis Obstet Gynecol. 2011;2011:1-9, https://doi. org/10.1155/2011/942937.

8. Nurminen T, Lusa S, Ilmarinen J, Kurppa K. Physical work load, fetal development and course of pregnancy. Scand J Work Environ Health. 1989;15(6):404-14.

9. Del Valle JF, Lopez M, Bravo A. Job stress and burnout in residential child care workers in Spain. Psicothema. 2007;19(4):610-5.

10. Moher D, Liberati A, Tetzlaff J, Altman DG. Preferred reporting items for systematic reviews and meta-analyses: the PRISMA statement. PLoS Med. 2009;6(7):e1000097, https://doi.org/10.1371/journal.pmed.1000097.

11. Vandenbroucke JP, von Elm E, Altman DG, Gotzsche PC, Mulrow CD, Pocock SJ, et al. Strengthening the Reporting 
of Observational Studies in Epidemiology (STROBE): explanation and elaboration. PLoS Med. 2007;4(10):e297, https://doi.org/10.1371/journal.pmed.0040297.

12. Rocheleau CM, Bertke SJ, Lawson CC, Romitti PA, Desrosiers TA, Agopian AJ, et al. Factors associated with employment status before and during pregnancy: Implications for studies of pregnancy outcomes. Am J Ind Med. 2017;60(4):329-41, https://doi.org/10.1002/ajim.22700.

13. Savitz DA, Whelan EA, Rowland AS, Kleckner RC. Maternal employment and reproductive risk factors. Am J Epidemiol. 1990;132(5):933-45.

14. Adler SP. Cytomegalovirus and child day care. Evidence for an increased infection rate among day-care workers. New Eng J Med. 1989;321(19):1290-6, https://doi.org/10.1056/ NEJM198911093211903.

15. McDonald AD, McDonald JC, Armstrong B, Cherry NM, Cote R, Lavoie J, et al. Congenital defects and work in pregnancy. Br J Ind Med. 1988;45(9):581-8, https://doi.org/ 10.1136/oem.45.9.581.

16. McDonald AD, McDonald JC, Armstrong B, Cherry N, Delorme $\mathrm{C}$, Nolin $\mathrm{AD}$, et al. Occupation and pregnancy outcome. Br J Ind Med. 1987;44(8):521-6, https://doi.org/ 10.1136/oem.44.8.521.

17. McDonald AD, McDonald JC, Armstrong B, Cherry NM, Cote R, Lavoie J, et al. Fetal death and work in pregnancy. Br J Ind Med. 1988;45(3):148-57, https://doi.org/10.1136/ oem.45.3.148.

18. McDonald AD, McDonald JC, Armstrong B, Cherry NM, Nolin AD, Robert D. Prematurity and work in pregnancy. Br J Ind Med. 1988;45(1):56-62, https://doi.org/10.1136/ oem.45.1.56.

19. Luke B, Mamelle N, Keith L, Munoz F, Minogue J, Papiernik E, et al. The association between occupational factors and preterm birth: a United States nurses' study. Research Committee of the Association of Women's Health, Obstetric, and Neonatal Nurses. Am J Obstet Gynecol. 1995;173(3 Pt 1):849-62, https://doi.org/10.1016/0002-9378 (95)90354-2.
20. Armstrong BG, Nolin AD, McDonald AD. Work in pregnancy and birth weight for gestational age. Br J Ind Med. 1989;46(3):196-9, https://doi.org/10.1136/oem.46.3.196.

21. Mamelle N, Laumon B, Lazar P. Prematurity and occupational activity during pregnancy. Am J Epidemiol. 1984;119(3):309-22, https://doi.org/10.1093/oxfordjournals. aje.a113750.

22. Gothe CJ, Hillert L. Spontaneous abortions and work in day nurseries. Acta Obstet Gynecol Scand. 1992;71(4):284-92.

23. Riipinen A, Sallmen M, Taskinen H, Koskinen A, Lindbohm ML. Pregnancy outcomes among daycare employees in Finland. Scand J Work Environ Health. 2010;36(3):222-30.

24. LinS, Herdt-Losavio ML, Chapman BR, Munsie JP, Olshan AF, Druschel CM. Maternal occupation and the risk of major birth defects: a follow-up analysis from the National Birth Defects Prevention Study. Int J Hyg Environ Health. 2013;216(3): 317-23, https://doi.org/10.1016/j.ijheh.2012.05.006.

25. Olsen JH, de Nully Brown P, Schulgen G, Jensen OM. Parental employment at time of conception and risk of cancer in offspring. Eur J Cancer. 1991;27(8):958-65, https://doi. org/10.1016/0277-5379(91)90258-f.

26. Hersoug LG, Benn CS, Simonsen JB, Kamper-Jorgensen M, Linneberg A. Maternal employment in child-care institutions and the risk of infant wheeze and atopic dermatitis in the offspring. Pediatr Allergy Immunol. 2008;19(8):688-95, https://doi.org/10.1111/j.1399-3038.2008.00722.x.

27. Lamarre V, Gilbert NL, Rousseau C, Gyorkos TW, Fraser WD. Seroconversion for cytomegalovirus infection in a cohort of pregnant women in Quebec, 2010-2013. Epidemiol Infect. 2016;144(8):1701-9, https://doi.org/10.1017/ S0950268815003167.

28. Johnson J, Anderson B, Pass RF. Prevention of maternal and congenital cytomegalovirus infection. Clin Obstet Gynecol. 2012;55(2):521-30, https://doi.org/10.1097/GRF.0b01 3e3182510b7b.

29. Tookey P, Peckham CS. Does cytomegalovirus present an occupational risk? Arch Dis Child. 1991;66(9):1009-10, https:// doi.org/10.1136/adc.66.9.1009. 
30. Friedman S, Ford-Jones EL. Congenital cytomegalovirus infection - An update. Paediatr Child Health. 1999;4(1):35-8, https://doi.org/10.1093/pch/4.1.35.

31. Adler SP. Cytomegalovirus and pregnancy. Curr Opin Obstet Gynecol. 1992;4(5):670-75.

32. Joseph SA, Beliveau C, Muecke CJ, Rahme E, Soto JC, Flowerdew $\mathrm{G}$, et al. Cytomegalovirus as an occupational risk in daycare educators. Paediatr Child Health. 2006;11(7):401-7, https://doi.org/10.1093/pch/11.7.401.

33. Ford-Jones EL, Kitai I, Davis L, Corey M, Farrell H, Petric $\mathrm{M}$, et al. Cytomegalovirus infections in Toronto child-care centers: a prospective study of viral excretion in children and seroconversion among day-care providers. Pediatr Infect Dis J. 1996;15(6):507-14.

34. Jackson LA, Stewart LK, Solomon SL, Boase J, Alexander ER, Heath JL, et al. Risk of infection with hepatitis A, B or $\mathrm{C}$, cytomegalovirus, varicella or measles among child care providers. Pediatr Infect Dis J. 1996;15(7):584-9.

35. Joseph SA, Beliveau C, Muecke CJ, Rahme E, Soto JC, Flowerdew G, et al. Risk factors for cytomegalovirus seropositivity in a population of day care educators in Montreal, Canada. Occup Med (Lond). 2005;55(7):564-7.

36. Murph JR, Baron JC, Brown CK, Ebelhack CL, Bale JF Jr. The occupational risk of cytomegalovirus infection among day-care providers. JAMA. 1991;265(5):603-8.

37. Pass RF, Hutto C, Lyon MD, Cloud G. Increased rate of cytomegalovirus infection among day care center workers. Pediatr Infect Dis J. 1990;9(7):465-70.

38. Soto JC, Vincelette J, Belanger L. Cytomegalovirus infection as an occupational hazard among women employed in day-care centers. Pediatrics. 1994;94(Suppl):S1031.

39. Volpi A, Pica F, Cauletti M, Pana A, Rocchi G. Cytomegalovirus infection in day care centers in Rome, Italy: viral excretion in children and occupational risk among workers. J Med Virol. 1988;26(2):119-25.

40. Kiss P, De Bacquer D, Sergooris L, De Meester M, Vanhoorne M. Cytomegalovirus infection: An occupational hazard to kindergarten teachers working with children aged
2.5-6 years. Int J Occup Environ Health. 2002;8(2):79-86, https://doi.org/10.1179/107735202800338966.

41. Stelma FF, Smismans A, Goossens VJ, Bruggeman CA, Hoebe CJ. Occupational risk of human Cytomegalovirus and Parvovirus B19 infection in female day care personnel in the Netherlands; a study based on seroprevalence. Eur J Clin Microbiol Infect Dis. 2009;28(4):393-7, https://doi.org/ 10.1007/s10096-008-0635-y.

42. Van Rijckevorsel GG, Bovee LP, Damen M, Sonder GJ, Schim van der Loeff MF, van den Hoek A. Increased seroprevalence of IgG-class antibodies against cytomegalovirus, parvovirus B19, and varicella-zoster virus in women working in child day care. BMC Public Health. 2012;12:475, https:// doi.org/10.1186/1471-2458-12-475.

43. De Villemeur AB, Gratacap-Cavallier B, Casey R, BaccardLongere M, Goirand L, Seigneurin JM, et al. Occupational risk for cytomegalovirus, but not for parvovirus B19 in child-care personnel in France. J Infect. 2011;63(6):457-67, https://doi.org/10.1016/j.jinf.2011.06.012.

44. Stranzinger J, Kozak A, Schilgen B, Paris D, Nießen T, Schmidt L, et al. Are female daycare workers at greater risk of cytomegalovirus infection? A secondary data analysis of CMV seroprevalence between 2010 and 2013 in Hamburg, Germany. GMS Hyg Infect Control. 2016;11:Doc09, https:// doi.org/10.3205/dgkh000269.

45. Ornoy A, Ergaz Z. Parvovirus B19 infection during pregnancy and risks to the fetus. Birth Defects Res. 2017;109(5):31123, https://doi.org/10.1002/bdra.23588.

46. Watt AP, Brown M, Pathiraja M, Anbazhagan A, Coyle PV. The lack of routine surveillance of Parvovirus B19 infection in pregnancy prevents an accurate understanding of this regular cause of fetal loss and the risks posed by occupational exposure. J Med Microbiol. 2013;62(Pt 1):86-92, https://doi. org/10.1099/jmm.0.046714-0.

47. Gilbert NL, Gyorkos TW, Beliveau C, Rahme E, Muecke C, Soto JC. Seroprevalence of parvovirus B19 infection in daycare educators. Epidemiol Infect. 2005;133(2):299-304, https://doi.org/10.1017/s0950268804003474. 
48. Adler SP, Manganello AM, Koch WC, Hempfling SH, Best AM. Risk of human parvovirus B19 infections among school and hospital employees during endemic periods. J Infect Dis. 1993;168(2):361-8, https://doi.org/10.1093/infdis/ 168.2.361.

49. Gillespie SM, Cartter ML, Asch S, Rokos JB, Gary GW, Tsou CJ, et al. Occupational risk of human parvovirus B19 infection for school and day-care personnel during an outbreak of erythema infectiosum. JAMA. 1990;263(15):2061-5.

50. Cartter ML, Farley TA, Rosengren S, Quinn DL, Gillespie SM, Gary GW, et al. Occupational risk factors for infection with parvovirus B19 among pregnant women. J Infect Dis. 1991;163(2):282-5, https://doi.org/10.1093/infdis/ 163.2.282.

51. Riipinen A, Sallmen M, Hedman L, Ojajarvi A, Lindbohm ML, Meriluoto M, et al. Increased risk of human parvovirus B19 infection in day-care employees: a cohort study among pregnant workers during an epidemic in Finland. Occup Environ Med. 2014;71(12):836-41, https://doi. org/10.1136/oemed-2014-102217.

52. Valeur-Jensen AK, Pedersen CB, Westergaard T, Jensen IP, Lebech M, Andersen PK, et al. Risk factors for parvovirus B19 infection in pregnancy. JAMA. 1999;281(12):1099-105, https://doi.org/10.1001/jama.281.12.1099.

53. Jensen IP, Thorsen P, Jeune B, Moller BR, Vestergaard BF. An epidemic of parvovirus B19 in a population of 3,596 pre- gnant women: a study of sociodemographic and medical risk factors. BJOG. 2000;107(5):637-43.

54. Harger JH, Adler SP, Koch WC, Harger GF. Prospective evaluation of 618 pregnant women exposed to parvovirus B19: risks and symptoms. Obstet Gynecol. 1998;91(3):413-20.

55. Gyorkos TW, Beliveau C, Rahme E, Muecke C, Joseph S, Soto JC. High rubella seronegativity in daycare educators. Clin Invest Med. 2005;28(3):105-11.

56. Walker SP, Higgins JR, Permezel M, Brennecke SP, Phil D. Maternal work and pregnancy. Aust N Z J Obstet Gynaecol. 1999;39(2):144-51.

57. Shi L, Chia SE. A review of studies on maternal occupational exposures and birth defects, and the limitations associated with these studies. Occup Med (Lond). 2001;51(4):230-44, https://doi.org/10.1093/occmed/51.4.230.

58. Kinnula S, Tapiainen T, Renko M, Uhari M. Safety of alcohol hand gel use among children and personnel at a child day care center. Am J Infect Control. 2009;37(4):318-21, https:// doi.org/10.1016/j.ajic.2008.06.002.

59. Jefferson T, Del Mar C, Dooley L, Ferroni E, Al-Ansary LA, Bawazeer GA, et al. Physical interventions to interrupt or reduce the spread of respiratory viruses: systematic review. BMJ. 2009;339:b3675, https://doi.org/10.1136/bmj.b3675.

60. Aronson SS, Shope TRE. Managing Infectious Diseases in Child Care and Schools. A Quick Reference Guide. 4th ed. American Academy of Pediatrics; 2016.

This work is available in Open Access model and licensed under a Creative Commons Attribution-NonCommercial 3.0 Poland License - http://creativecommons.org/ licenses/by-nc/3.0/pl/deed.en. 